\title{
Global warming makes weather in boreal summer more persistent
}

\author{
Dim Coumou1,2† and Paolo De Luca $1 \uparrow$
}

1Department of Water and Climate Risk, Institute for Environmental Studies (IVM), Vrije Universiteit Amsterdam, Amsterdam, $1081 \mathrm{HV}$, the Netherlands

$5 \quad$ 2Royal Netherlands Meteorological Institute (KNMI), De Bilt, 3730 AE, the Netherlands

$\dagger$ These authors contributed equally to the work

Correspondence to: Dim Coumou (d.coumou@vu.nl)

Abstract. Extreme summer weather often has devastating impacts on society when it lasts for many days. Stalling cyclones

10 can lead to flooding and persistent hot-dry conditions can lead to health impacts and harvest losses. Global warming weakens the hemispheric-wide circulation in boreal summer, which has been shown in both observations and models using multiple circulation metrics. Until now, it is still largely unclear what this weakening implies for regional weather conditions, including their persistence. Using an advanced persistence metric, we show that summer weather has become more-persistent over 1979-2019. State-of-the-art climate models reproduce this upward trend in persistence indicating that it

15 can be attributed to greenhouse gas forcing. Our persistence metric accounts for the full state of the atmosphere at any given moment and is strongly rooted in dynamical systems theory. Thereby it is able to detect dynamical changes previously unseen in more widely used clustering analyses that sharply reduce the amount of information used. We show that under future high-emission scenarios, summer weather will become increasingly more-persistent due to a weakening of the circulation. Most of this increase in persistence, and the associated societal risks, is avoided under an emission scenario compatible with the Paris agreement.

\section{Introduction}

Global warming over the last decades has increased the frequency and intensity of heat (Coumou and Robinson, 2013; 25 Sillmann et al., 2013a, 2014) and rainfall (Lehmann et al., 2015; Westra et al., 2013) extremes, which is projected to continue with future warming (Sillmann et al., 2013b; Sillmann and Roeckner, 2008). Summer, with most biological and agricultural productivity, is probably the season when future changes in extremes will have the most severe impacts on humanity (Hansen et al., 2012). Recent record-breaking heatwaves in the mid-latitudes caused massive socio-economic impacts (Coumou and Rahmstorf, 2012) and such record-heat has already increased 5-fold since pre-industrial times

30 (Coumou et al., 2013; Rahmstorf and Coumou, 2011). Summer extremes often become most devastating when they last for many days and the recent decade has seen several such persistent extremes (Coumou and Rahmstorf, 2012; Fischer et al., 2007; Wehrli et al., 2020). In 2016, many municipalities in western Europe were flooded when a slow-moving continental- 
https://doi.org/10.5194/wcd-2020-40

Preprint. Discussion started: 28 August 2020

(C) Author(s) 2020. CC BY 4.0 License.
Weather and

Climate Dynamics

Discussions

scale low pressure system remained over Europe for two weeks leading to day after day of thunderstorms (Anon, 2016). In 2010, Russia saw 33 consecutive hot-and-dry days (above 30。C), resulting in grain harvest losses of 30\% (Barriopedro et al., 35 2011).

While in general there is substantial uncertainty associated with circulation changes within the climate system (Shepherd, 2014), there is now strong evidence that boreal summer circulation weakens with global warming (Chang et al., 2016; Coumou et al., 2015, 2018; Gertler and O'Gorman, 2019; Lehmann et al., 2014; O'Gorman, 2010; Routson et al., 2019).

40 Weakening of summertime westerlies and storm tracks is a robust feature supported by observations (Chang et al., 2016; Coumou et al., 2015), paleo-data (Routson et al., 2019), model simulations (Gertler and O'Gorman, 2019; Lehmann et al., 2014), physical understanding (Coumou et al., 2018; Hoskins and Woollings, 2015), and has been documented using multiple metrics (Chang et al., 2016; Coumou et al., 2015, 2018; Gertler and O'Gorman, 2019; Lehmann et al., 2014; O’Gorman, 2010; Petrie et al., 2015; Routson et al., 2019; Sussman et al., 2020). Since 2000, the Arctic has warmed at a rate 45 at least twice as fast as the global average (Cohen et al., 2020; Coumou et al., 2015, 2018). This decreases the temperature gradient between the Arctic and (sub) tropics and weakens the mid-latitude westerlies and storm tracks (Chang et al., 2016; Coumou et al., 2015, 2018; Gertler and O'Gorman, 2019; Lehmann et al., 2014; O'Gorman, 2010; Petrie et al., 2015; Routson et al., 2019). These dynamical changes in boreal summer are also seen in climate models under greenhouse gas forcing (Chang et al., 2016; Coumou et al., 2018).

It is much less clear what this weakening of large-scale summer circulation implies for regional weather conditions, including extremes. Some studies hypothesized that a weakening circulation would lead to more-persistent, and therefore more-extreme, summer weather (Pfleiderer et al., 2019). However, the dominant mechanisms behind weather persistence remain debated (Horton et al., 2016). Many factors can influence the occurrence of slow-moving high-pressure systems in 55 the mid-latitudes, or "blocks", including the strength of storm tracks and westerlies (Hoskins and Woollings, 2015), waveguide effects (Coumou et al., 2014; Manola et al., 2013), latent heating (Pfahl et al., 2015), tropical sea-surface temperatures (Trenberth and Fasullo, 2012) and monsoon activity (Di Capua et al., 2020; Ding and Wang, 2007). Also processes involving soil-atmosphere or ocean-atmosphere interactions can favor or sustain the associated large-scale flow patterns (Fischer et al., 2007; Haarsma et al., 2009; Lau et al., 2004; McKinnon et al., 2016; Teng and Branstator, 2019).

A central challenge remains how to best quantify weather persistence. Most studies so far applied some form of clustering technique, either in space or time, to reduce the dimensionality of the system (Horton et al., 2015; Huguenin et al., 2020; Pfleiderer and Coumou, 2018; Swain et al., 2016). Typically, similar circulation states are clustered together into one particular weather regime, and consecutive days in the same regime then give persistence. However, this dimensionality 65 reduction step removes most of the available information and thus hampers proper statistics. The choice of dimensionality (i.e. the number of clusters) is often arbitrary and the results can be very sensitive to such choice. Moreover, clustering 
https://doi.org/10.5194/wcd-2020-40

Preprint. Discussion started: 28 August 2020

(c) Author(s) 2020. CC BY 4.0 License.

(c) (1)
Weather and

Climate Dynamics

Discussions

methods are typically not well suited for summer circulation as the dynamical system behaves in a more continuous fashion rather than in clearly separated clusters or regimes (Cortesi et al., 2019). Finally, the warming and associated expansion of the lower atmosphere can distort trend analyses based on clustering mid-to-upper level circulation (Horton et al., 2015;

70 Swain et al., 2016).

Here we apply a novel data analyses technique based on dynamical systems theory that accounts for the full state of the atmosphere at any given moment to estimate its persistence (Faranda et al., 2017a, 2019; Messori et al., 2017). We analyze recurrences along the trajectory (i.e. the evolution through phase-space) to estimate the system's dynamical properties,

75 without taking any a priori assumptions on its dimensionality. For all states $\zeta(\mathrm{t})$, in our case all available summer days, we also calculate the local dimensionality, capturing the number of directions to which the atmosphere can evolve, using nearby trajectories (Figure 1). Persistence $(\theta-1)$ is defined as the average residence time of trajectories in the neighborhood of $\zeta$ in units of days (see Methods). Figure 1a illustrates the method for a simplified chaotic system, highlighting one highdimensional state and one slowly evolving, low-dimensional state. Typically, a lower local dimension increases persistence

80 as there are fewer future states possible and thus the atmosphere is more likely to remain in a similar state (Faranda et al., 2017a). However, the speed of the trajectories through the neighborhood of $\zeta$ matters which is captured by $\theta-1$. The derivation relies on recent developments at the interface between dynamical systems theory and extreme value theory (see Methods) (Faranda et al., 2017b; Lucarini et al., 2016). This dynamical system approach has been applied to different climate variables and regions and was shown to accurately reflect large-scale features of atmospheric motions (Faranda et al.,

85 2017a, 2020; Hochman et al., 2019; De Luca et al., 2020b). Moreover, $\theta-1$ is indeed directly linked to the more conventional notion of persistence of weather regimes (Hochman et al., 2019). Figure 1b shows that daily $\theta-1$ timeseries clearly capture the very-persistent blocking circulation over Europe from early July to mid-August 2010. 


\section{(a)}
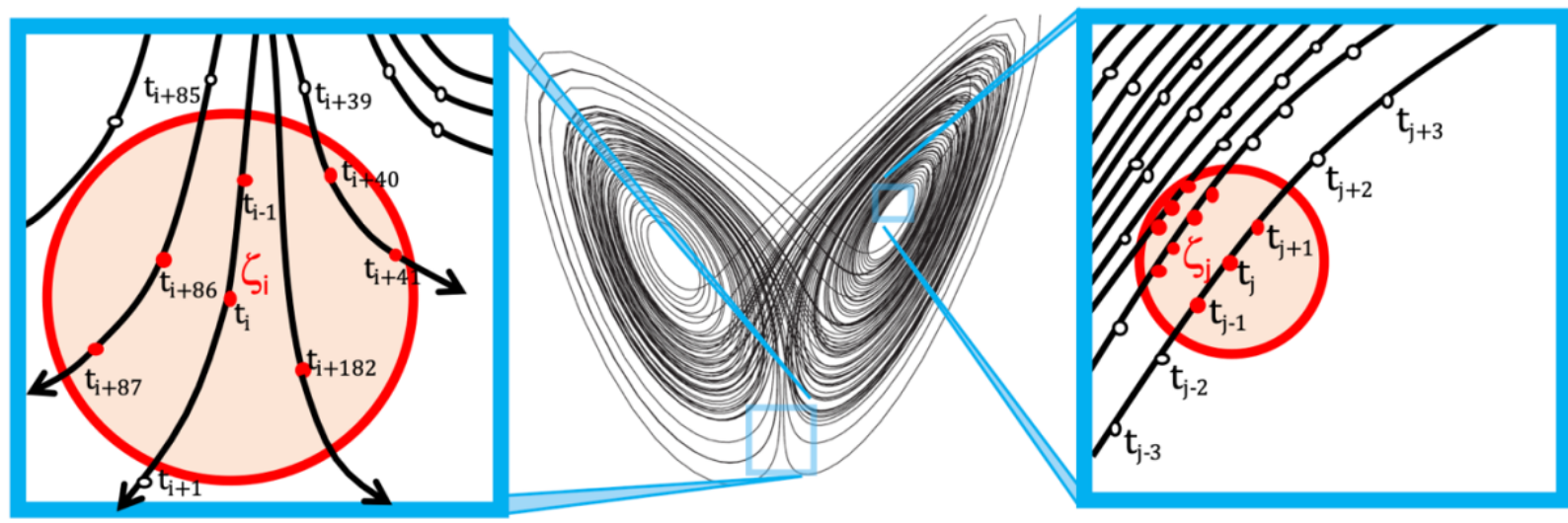

(b)

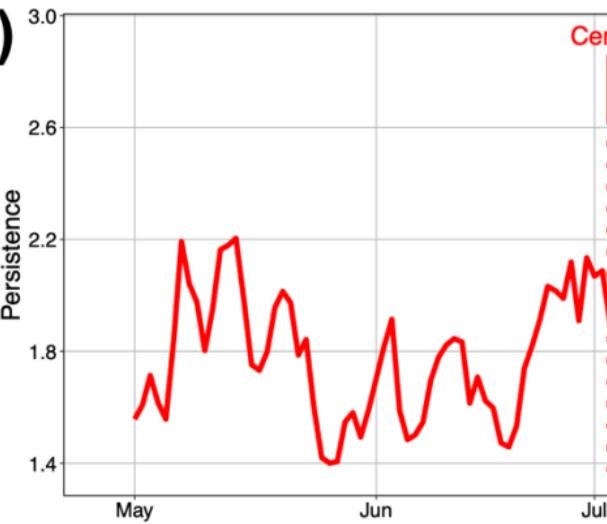

Figure 1. Schematic illustration of dynamical system approach. (a) Attractor through phase space for a simplified chaotic system zooming in on (left) a state $\zeta_{\mathrm{i}}$ with large local dimensionality (the system can evolve to many different type of new states) and (right) a low-dimensional and slowly evolving state $\zeta_{\mathrm{j}}$ with large persistence $\theta-1$. Red dots represent recurrences around states $\zeta_{\mathrm{i}}$ and $\zeta_{\mathrm{j}}$. (b) Daily persistence $\theta-1$ over CEU during 2010 highlighting the very persistent circulation during the period of the Russian heatwave from early July to mid-August ( $8 \%$ of days exceed the $99_{\text {th }}$ percentile for $\theta-1$ ).

\section{Methods}

\subsection{Dynamical systems metrics}

Here, we use a dynamical systems approach to compute metrics of daily local persistence $(\theta-1)$ and local dimension (d) of a given selected atmospheric variable, in our case being geopotential height at 500mb (Z500) and sea-level pressure (SLP), over 16 mid-latitude regions (using Nicholls and Seneviratne (2010) IPCC 'SREX' regions, plus three regions representing the full mid-latitude belt, north Atlantic and north Pacific ocean basins). $\theta_{-1}$ quantifies the average residence time of trajectories through phase-space in the direct neighborhood of a state of interest $(\zeta)$. Therefore, when $\theta-1$ has higher values, it is the more likely that the preceding and future states resemble the current state over sufficiently long timescales (Faranda et 
al., 2017b; Messori et al., 2017). On the other hand, d can be described as a proxy for the degrees of freedom active around $\zeta$ and therefore it provides a measure of the number of possible configurations that the system may evolve to. Low (high) values of $\mathrm{d}$ refer to more (less) predictable configurations. The calculation of $\theta_{-1}$ and d originates from the combination of Poincaré recurrences with extreme value theory (Freitas et al., 2010; Lucarini et al., 2012, 2016). Recurrences are states of the system that return arbitrarily close to a previously visited state (see red dots in Figure 1a). By considering one atmospheric variable $x$ and a state of interest $\zeta, \theta-1$ and $\mathrm{d}$ are computed over a latitude-longitude map for each day of $x$ timeseries. Therefore, recurrences are states that are close to $\zeta$ in the phase-space, and thus those that have configurations that are very similar to $\zeta$, for the selected variable. Recurrences in the phase-space are defined using the Euclidean norm (dist) between $\zeta$ and nearby states. The metric $\theta_{-1}$ has the same units as the temporal resolution of the analyzed variable and therefore in our case it has units of days.

To compute recurrences one has to first define an observable via logarithmic returns as follows:

$g(x(t), \zeta)=-\log [\operatorname{dist}(x(t), \zeta)]$

120

Where $x(t)$ represents the complete time-series of the variable $x$ and $\zeta$ the given state of interest. Note that the total number of states equals the number of time-steps in the full time-series and recurrences are computed for each state. Then, a sufficient high-quantile threshold $\mathrm{s}(\mathrm{q}, \zeta)$ is defined for the time-series $\mathrm{g}(\mathrm{x}(\mathrm{t}), \zeta)$, so that $\forall \mathrm{g}(\mathrm{x}(\mathrm{t}), \zeta)>\mathrm{s}(\mathrm{q}, \zeta)$ is possible to define a recurrence as $\mathrm{u}(\zeta)=\mathrm{g}(\mathrm{x}(\mathrm{t}), \zeta)$-s $(\mathrm{q}, \zeta)$. The cumulative distribution function of the recurrences $\mathrm{F}(\mathrm{u}, \zeta)$ converges to the exponential member of the Generalized Pareto Distribution (GPD)(Freitas et al., 2010; Lucarini et al., 2016) as follows:

$F(u, \zeta) \simeq \exp \left[-\vartheta(\zeta) \frac{u(\zeta)}{\sigma(\zeta)}\right]$

Where the parameters $\theta$ and $\sigma$ are sensible to the chosen state $\zeta$. The parameter $\theta$ represents the extremal index (Moloney et 130 al., 2019) and is here computed using the approach in (Süveges, 2007). Finally, our local persistence metric corresponds to $\theta-1=\Delta \mathrm{t} / \theta$, where in our case $\Delta \mathrm{t}=1$ day and the local dimension is derived as $\mathrm{d}(\zeta)=1 / \sigma(\zeta)$.

Our dynamical systems approach to compute $\theta-1$ and $\mathrm{d}$, which from now on we will refer to as persistence and dimension, has been successfully applied to a different set of univariate (Faranda et al., 2017b, 2017a, 2019; Messori et al., 2017) and multivariate (Faranda et al., 2020; De Luca et al., 2020a, 2020b) case-studies. For more details on the definition of persistence and dimension we refer the reader to (Faranda et al., 2017b, 2019; Messori et al., 2017).

\subsection{Mid-latitude regions}


https://doi.org/10.5194/wcd-2020-40

Preprint. Discussion started: 28 August 2020

(C) Author(s) 2020. CC BY 4.0 License.
Weather and

Climate Dynamics

Discussions

In our work we use a total of 16 mid-latitude regions over the northern hemisphere to quantify observed, historical and projected changes in daily persistence and dimension (Faranda et al., 2017b; Messori et al., 2017). 13 of these 16 regions are the ones defined in the IPCC Fifth Assessment Report (AR5, see here): ALA, CAS, CEU, CGI, CNA, EAS, ENA, MED, NAS, NEU, TIB, WAS and WNA. In addition to these, we added 3 more regions covering the full mid-latitude belt (MIDLAT, -180W, 180E, 30N, 70N), North Atlantic (NA, -48E, -10E, 45N, 75N) and North Pacific (NP, -190E, -135E, 30N, $56 \mathrm{~N}$ ) ocean basins (Figure 2a).

\subsection{Data}

In this study, we use of European Centre for Medium-Range Weather Forecast (ECMWF) reanalysis dataset ERA5(C3S, 2017) at $0.25^{\circ}$ of horizontal resolution (freely available here) and Coupled Model Intercomparison Project Phase 6 (CMIP6) (Eyring et al., 2016; O’Neill et al., 2016) datasets (freely available here). From CMIP6 data we use a multi-model ensemble

150 (MME) of Historical along with Shared Socioeconomic Pathways (SSP) 126 and SSP585 runs. From these datasets we extract three atmospheric variables at daily time-steps, namely geopotential height at 500mb (Z500, m), U wind-speed (ms-1) at 500mb and sea-level pressure (SLP, mb). Daily persistence and dimension have been computed for both Z500 and SLP, the latter used as a sensitivity test. For Z500, a total of 15, 22 and 23 CMIP6 models compose our Historical, SSP126 and SSP585 MMEs respectively (Table S1). Similarly, our SLP Historical MME is composed by 15 CMIP6 models (Table S1).

155 Lastly, U wind MMEs are composed by 17, 21 and 21 CMIP6 models for Historical, SSP126 and SSP585 (Table S1). Note that for dimension we show its observed and historical trends to strengthen our interpretation of persistence. The models have been chosen following data availability from the World Climate Research Programme (WCRP) website. For each CMIP6 model the first available ensemble member has been chosen (Table S1). We analyzed CMIP6 data on the original horizontal resolution of each individual model (Table S1), to limit the number of pre-processing steps that might influence

160 the dynamical system. The ERA5 time-period spans across 1979-2019, whereas for Historical and SSPs periods we choose 1979-2014 (based on availability) and 2081-2100. In total, 1232 full-year datasets have been used to compute Z500 and SLP daily persistence and dimension across the 16 mid-latitude regions, ERA5 and CMIP6 data. Then, we filtered boreal summer June-July-August (JJA) daily persistence and dimension outputs from all the years under study. However, we would like to note that a very small number of CMIP6 datasets contain missing values, making it impossible to compute the dynamical systems metrics. These 12 datasets, excluded from the analyses, are listed in Table S2.

\section{Climatology of summer persistence}

First, we analyze the climatology and intra-seasonal behavior of persistence $(\theta-1)$ in different mid-latitude regions. In early summer, persistence is low and it progressively increases over June to peak around the end of July or early August (i.e. day $\sim 60$ in Figure 2). This intra-seasonal evolution is mirrored by the strength of the westerlies, which are weakest in JulyAugust for mid-latitude regions (Figure S1). June can be considered a transition month with the jets still relatively strong and propagating northwards from their southerly position in the cold season. The 'high' summer months July and August are 
https://doi.org/10.5194/wcd-2020-40

Preprint. Discussion started: 28 August 2020

(c) Author(s) 2020. CC BY 4.0 License.

(c) (1)

Weather and

Climate Dynamics

Discussions

characterized by the weakest westerlies, smallest poleward temperature gradients, and most pronounced weather persistence. Climate models of the Coupled Model Intercomparison Project - Phase 6 (CMIP6, Table S1) capture this intra-seasonal 175 evolution well. The multi-model mean reproduces the strength and seasonality of the westerlies, though individual models might have biases (Figure S1). The intra-seasonal evolution of persistence is also well reproduced but models tends to overestimate persistence (by about 5\%, Figure 2). This might be related to a general underestimation of variability in models suggesting that models have a too small local dimensionality, and thus the current state is more likely to persist. We focus on July and August as they behave dynamically similar and since these are the hottest months and thus persistent weather will 180 have the most pronounced impacts. Analyses based on all summer months give very similar results (not shown). 
(a)

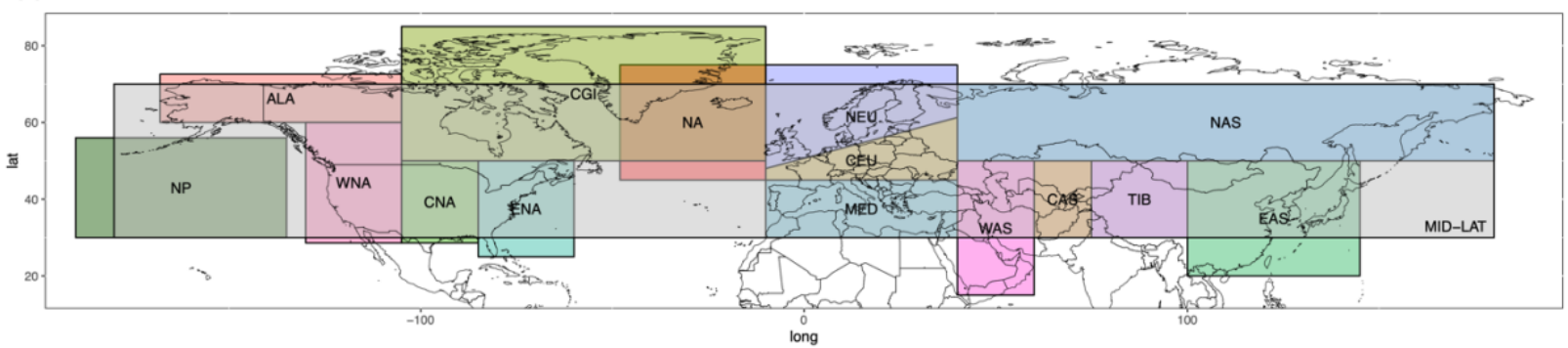

(b) ALA
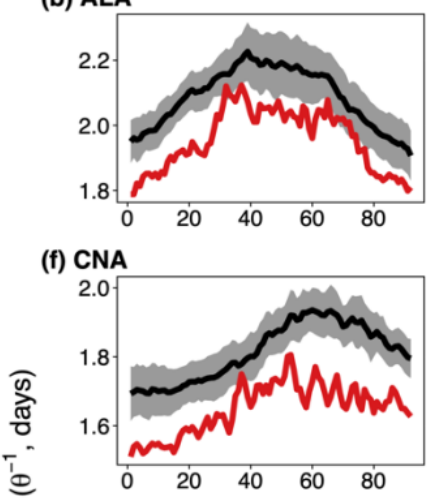

(c) CAS

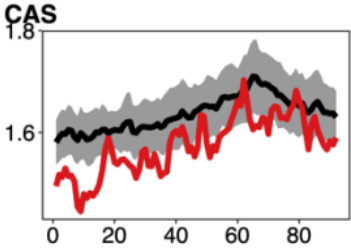

(g) EAS

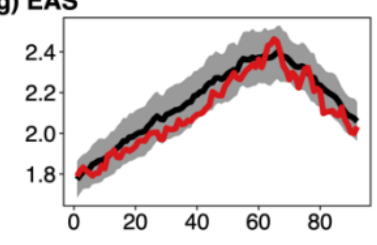

(k) NAS

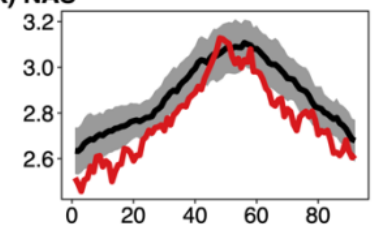

(o) TIB
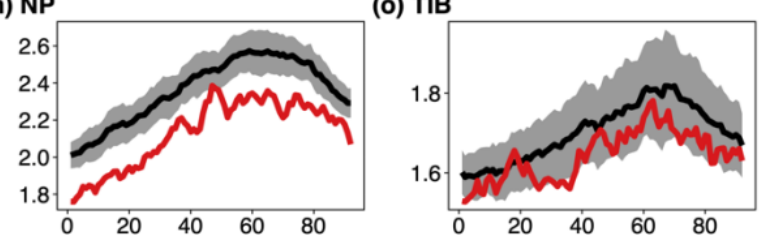

(d) CEU

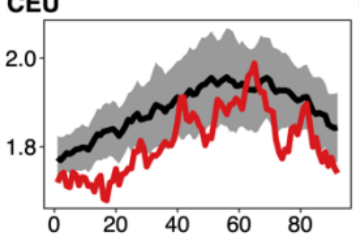

(e) CGI

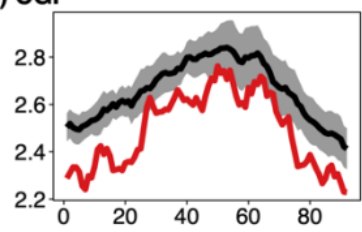

(h) ENA

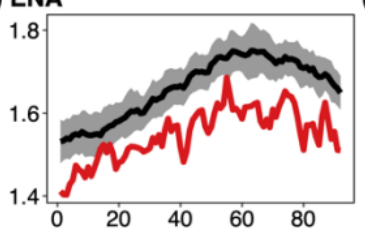

(i) MED

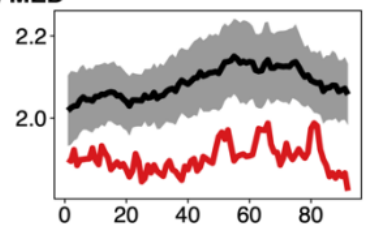

(m) NA
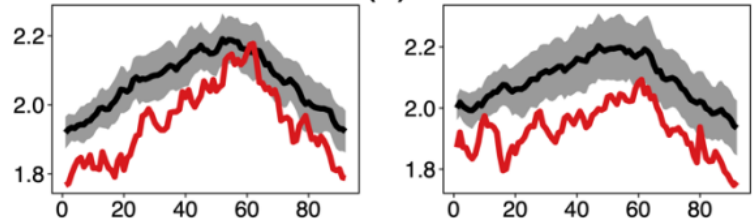

(q) WNA

(p) WAS

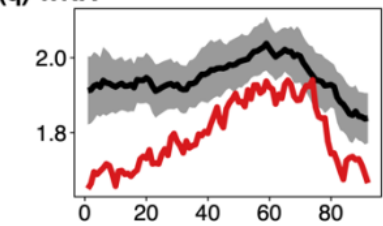

JJA Days

- ERA5 - Historical

Figure 2. Intra-seasonal evolution of weather persistence in boreal summer showing most persistent circulation by end of July to early August. (a) The 16 mid-latitude regions over the northern hemisphere used in the analyses: 13 IPCC-

185 SREX regions, full mid-latitude belt (MID-LAT), North Atlantic (NA) and North Pacific (NP) oceans (see Methods). (b)-(q) Climatological persistence during summer days (June-July-August) for ERA5 1979-2019 (in red) and historic climate simulations 1979-2014 (multi-model ensemble mean in black and 95\% model-range in grey-shading) for the mid-latitude regions shown in panel (a). See Table S1 for CMIP6 data used in the analyses. 
https://doi.org/10.5194/wcd-2020-40

Preprint. Discussion started: 28 August 2020

(c) Author(s) 2020. CC BY 4.0 License.

(c) (1)
Weather and

Climate Dynamics

Discussions

\section{4. Historical trends in observations and models}

Weather persistence in July-August has clearly increased over the last 40 years (Figure 3 and Table S3), both in observations (ERA5 reanalysis, C3S (2017)) and state-of-the-art climate models (CMIP6, Eyring et al. (2016)). Over the mid-latitude belt $\left(30^{\circ} \mathrm{N}-70^{\circ} \mathrm{N}\right)$, the mean weather persistence has increased by about $10 \%$ over $1979-2019$. Historic model simulations over 1979-2014 (simulations with historic forcings end in 2014 - see Methods) have an upward trend of similar magnitude. The

195 close agreement between modeled and observed trends strongly suggests that the observed increase in persistence is attributable to greenhouse gas forcing. The most pronounced and significant $(\mathrm{p}<0.01)$ trends in persistence are observed over the Atlantic sector, in particular Europe (NA, CGI, CEU, NEU and MED). Here persistence increased about twice as fast as compared to other mid-latitude regions. This is consistent with the pronounced weakening observed for the NorthAtlantic storm track reported in previous studies (Chang et al., 2016; Lehmann and Coumou, 2015). Moreover, slowly evolving circulation states, i.e. those that are more relevant for persistent extremes, have also become more persistent since 1979, as revealed by trend analyses of the 90th percentile of $\theta_{-1}$ (Figure S2 and Table S4). In fact, the magnitude of the upward trend is nearly twice as large for the 90th percentile as compared to the mean (Figure S3). Just like changes in the mean, the trends for the 90th percentile are most pronounced for the Atlantic sector. We repeated the analyses using sea-level pressure and found similar significant trends for the mid-latitudes though on a regional scale the trends are less significant (Figure S4 and Table S5). Consistent with upward trends in $\theta_{-1}$, the local dimensionality has seen a progressive decline since 1979 in both observations and CMIP6 models (Figure S5 and Table S6). High persistence and low dimension are linked to more stable states (Faranda et al., 2017a; De Luca et al., 2020b; Messori et al., 2017). 
(a) ALA
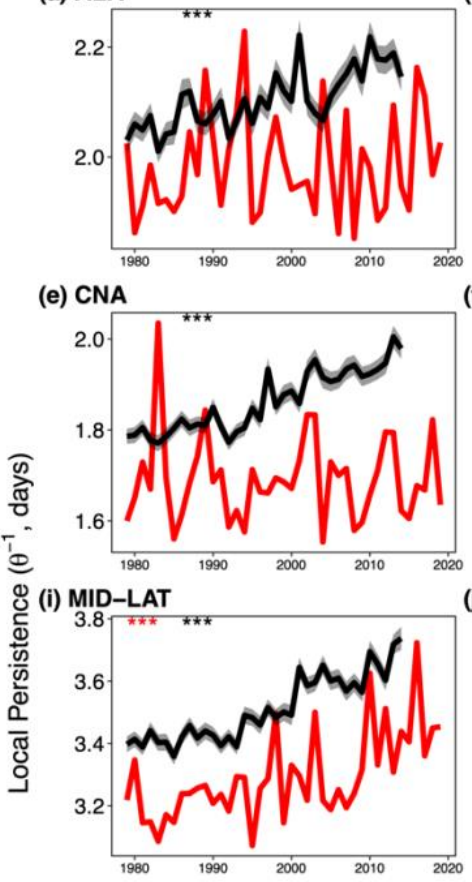

(m) NP

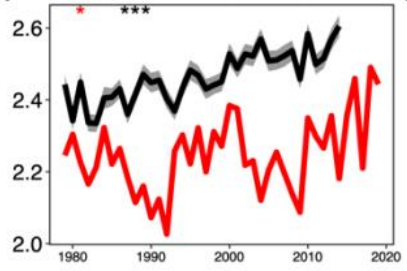

(b) CAS

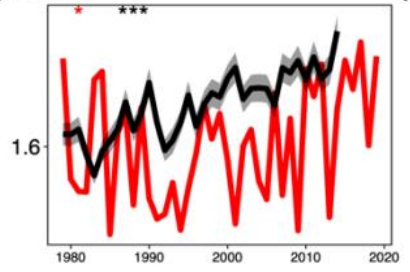

(f) EAS

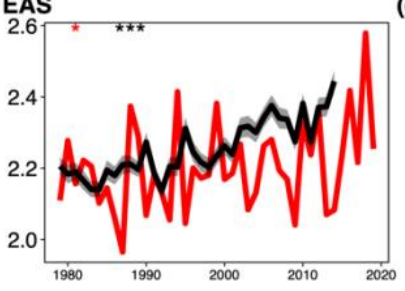
(j) NAS

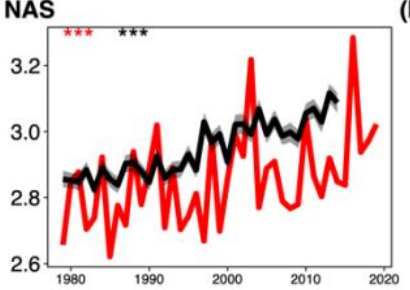

(n) TIB

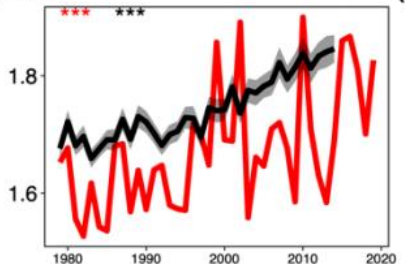

(c) CEU

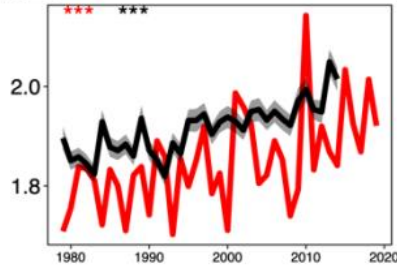

(g) ENA

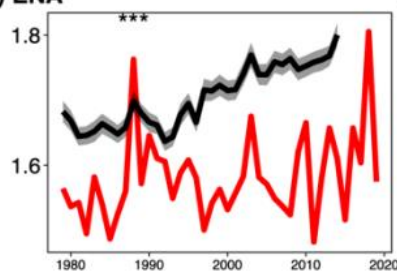

(k) NEU

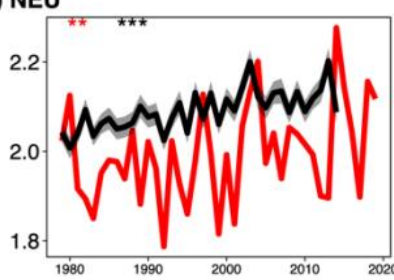

(o) WAS

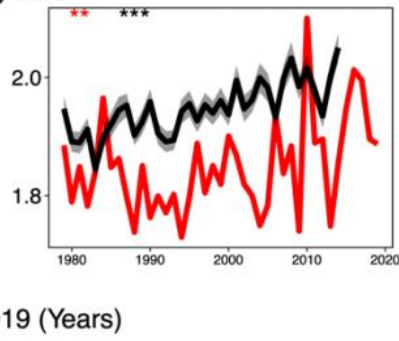

(d) CGI

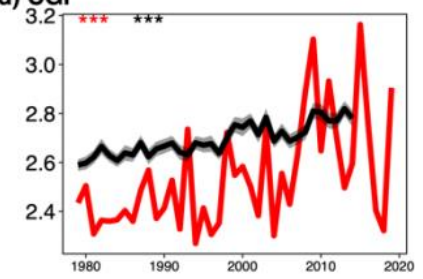

(h) MED

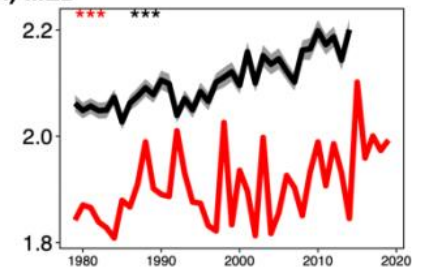

(I) NA

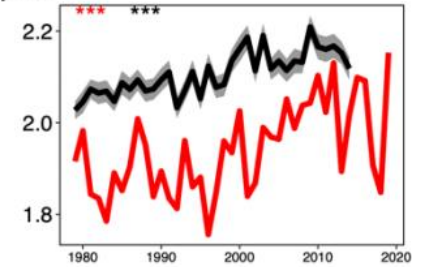

(p) WNA

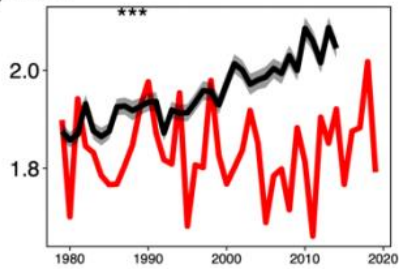

Time 1979-2019 (Years)

- ERA5 - Historical

Figure 3. Significant upward trends since 1979 in the mean weather persistence during July-August. July-August mean persistence for ERA5 1979-2019 (in red) and historic climate simulations 1979-2014 (multi-model mean in black and 95\% confidence intervals in grey-shading) for different mid-latitude regions as shown in Figure 1a. Stars indicate significance of the trends using a Mann-Kendall test with *** $\mathrm{p}<0.01 ; * * \mathrm{p}<0.05$; and $* \mathrm{p}<0.1$.

\section{Future changes in persistence}

Climate model simulations (O’Neill et al., 2016) show that future greenhouse gas emissions will further increase persistence in boreal summer (Figure 4 and Table S7). Under a low emission scenario (SSP126, compatible with the Paris climate agreement), the future increase in persistence will be moderate- and in fact less than the changes observed over the last 40 years (green box-and-whisker plots in Figure 4). Under a high-emission scenario (SSP585), resulting in a world about $4^{\circ} \mathrm{C}$ 
warmer than pre-industrial, the increase in persistence is about a factor 2 to 3 larger (compare blue and green box-andwhisker plots in Figure 4). The model spread is substantial but all models except one project an increase in persistence for the mid-latitude belt. The most pronounced future changes are seen over the American sector (CGI, CNA, WNA - red labels in Figure 4) and Asia (EAS, NAS - purple labels in Figure 4). Europe - in contrast to the historic changes - sees a more moderate increase in persistence. In general, land-areas see a more pronounced increase as compared to the oceans (NA, NP), roughly by a factor 1.4. Regression analyses between end-of-century changes (2081-2100 minus 1981-2000) in persistence and westerlies behave approximately linearly with a weakening of the westerlies by $-1 \mathrm{~m} / \mathrm{s}$ increasing the persistence with nearly half a day (Figure S6).

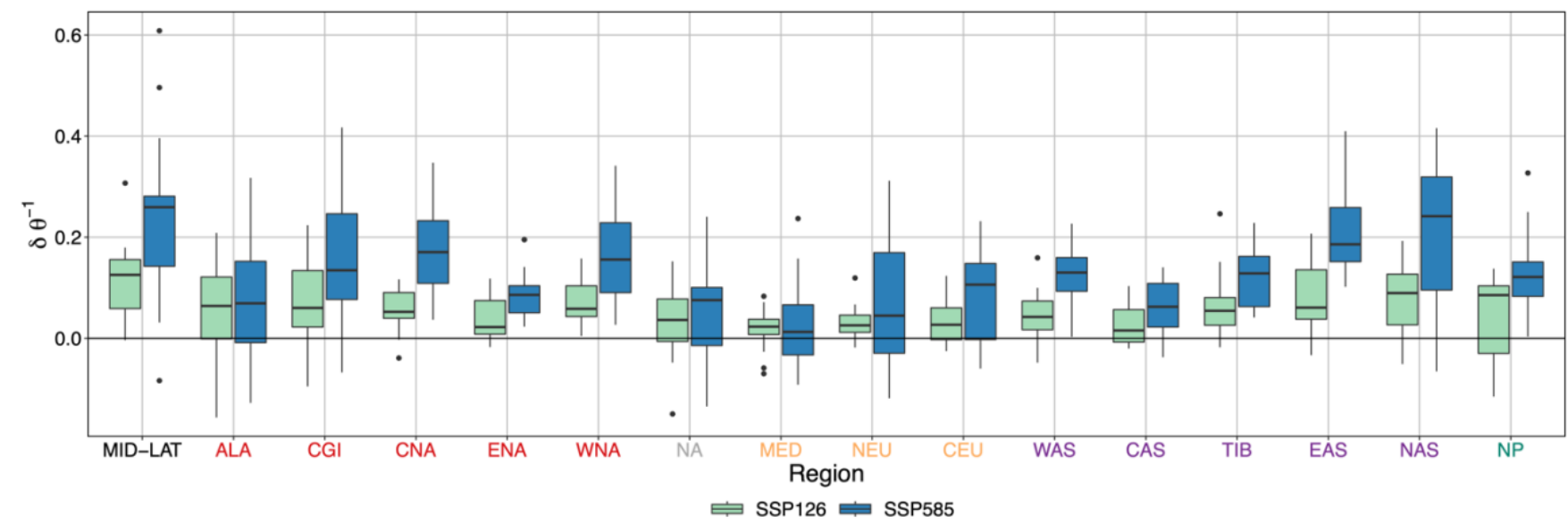

Figure 4. End of century changes in the mean weather persistence during July-August. Box and whisker plots of the change in persistence $(\delta \theta-1)$ between 2081-2100 and 1981-2000 (historical simulation runs) under SSP126 (green) and SSP585 (blue). Changes are highly significant according to a one tailed Mann-Whitney test (see Table S7).

\section{Discussion}

240 Here we reported detectable increases in weather persistence over the historic period (post 1979) in both observations and climate models. We argue that, to detect such signal, advanced persistence metrics, as used here, are essential. More widely used clustering approaches take strong assumptions on the system's dimensionality, and the dimensionality reduction removes most of the available data: The complex state of the atmosphere on any given day is reduced to a single regime classification. Any remaining signal is subsequently smeared out over multiple clusters. A fairly weak signal in a system with pronounced variability will be lost in such analyses.

The detected upward trend in persistence can be linked to a weakening of the westerlies associated with a reduction in poleward temperature gradient (as shown e.g. in Coumou et al. (2015)). In summer, Arctic amplification manifests itself as 
https://doi.org/10.5194/wcd-2020-40

Preprint. Discussion started: 28 August 2020

(c) Author(s) 2020. CC BY 4.0 License.
Weather and

Climate Dynamics

Discussions

enhanced warming over land areas around $65^{\circ} \mathrm{N}$ (Coumou et al., 2018). The Arctic Ocean shows no strong warming amplification in summer as all the extra energy absorbed is used to melt sea-ice - not to raise temperatures. In contrast, the Arctic land-areas (Siberia, Canada, Alaska) have seen very strong warming associated with reductions in snow cover (Connolly et al., 2019). This enhanced high-latitude land warming in summer has also been formerly attributed to be likely (following the IPCC lexicon) due to greenhouse gas forcing (Mann et al., 2017). The warming penetrates the lower atmosphere (up to $\sim 500 \mathrm{mb}$ ) (Cohen et al., 2014; Coumou et al., 2015) and thus weakens the westerlies. Following the thermal-wind balance, the strength of the westerlies scale with the vertical integral of the poleward temperature gradient and thus lower atmospheric layers have a strong influence on the upper-level flow. Here we show that this weakening has already induced more-persistent summer weather throughout the mid-latitudes.

Some studies argued that the reduction in day-to-day weather variability associated with weakened storm tracks would imply fewer extremes (Schneider et al., 2014). However, we argue that a reduced day-to-day variability reflects a lowering of the local dimensionality, directly related to the number of directions in phase-space in which the atmosphere can evolve. If this number reduces, then the current state is more likely to last longer, favoring long-lived, stalling weather events. These tend to be the extremes that matter to society. The future increase in dynamical persistence, as reported here, is in agreement with studies showing that the number of consecutive summer days with either warm, cold, dry or wet anomalies is projected to increase (Schleussner et al., 2017).

The increase in summer weather persistence since 1979 has been particularly pronounced over the North Atlantic sector including Europe, and especially in the upper tail of $\theta_{-1}$ (90th percentile). This might have contributed to the exceptional increase in European heatwaves (Christidis et al., 2014). Persistent summers include the Russian heatwave of 2010 (Barriopedro et al., 2011) and hot-and-dry summers over western Europe in 2018 and 2019. The strong increase in persistence over the Atlantic appears consistent with the recently reported increase in stalling Hurricanes along the North American coast (Hall and Kossin, 2019). The zonal mean dynamical changes, as described above, can regionally be exacerbated by ocean-atmosphere or land-atmosphere interactions. The strengthened land-ocean temperature contrast - a direct thermodynamic consequence of greenhouse gas forcing - promotes quasi-stationary waves (Shaw and Voigt, 2015).

275 Likewise, the atmospheric response to a weakened Atlantic Meridional Overturning Circulation (Caesar et al., 2018) generates blocking high-pressure systems over Europe in summer (Haarsma et al., 2015). Finally, also, soil-moisture feedbacks can generate regional (Fischer et al., 2007; Haarsma et al., 2009) or even hemispheric (Teng and Branstator, 2019) circulation changes.

280 We have reported an overall increase in the persistence of boreal summer weather using an advanced metric based on dynamical systems analyses. State-of-the-art climate models show similar upward trends suggesting that the increased persistence since 1979 is attributable to greenhouse gas forcing. Consequently, future projections show substantial further 
https://doi.org/10.5194/wcd-2020-40

Preprint. Discussion started: 28 August 2020

(c) Author(s) 2020. CC BY 4.0 License.
Weather and

Climate Dynamics

Discussions

increases in persistence under high-emission scenarios. This poses serious risks for society as it increases the risk of stalling weather patterns. These future risks are mostly avoided under emission scenarios that are compatible with the Paris agreement.

\section{Author Contributions}

DC designed the study, wrote the manuscript and created Figure 1a. PDL prepared the data, performed the analyses, created the figures, contributed to the methods and helped in writing the manuscript.

\section{Competing interests}

295 The authors declare that they have no conflicts of interest.

\section{Acknowledgments}

This is TiPES contribution \#32. This project has received funding from the European Union's Horizon 2020 research and innovation programme under grant agreement No. 820970. The data analysis has been performed thanks to the VU HPC

BAZIS-cluster.

\section{References}

305 Anon: DWD Pressemitteilung - Globale Temperaturrekorde und Sturzfluten in Deutschland - Vorgeschmack auf die Sommer der Zukunft?, 2016.

Barriopedro, D., Fischer, E. M., Luterbacher, J., Trigo, R. M. and García-Herrera, R.: The Hot Summer of 2010: Redrawing the Temperature Record Map of Europe, Science, 332(6026), 220-224, 2011.

C3S: ERA5: Fifth generation of ECMWF atmospheric reanalyses of the global climate, Copernicus Clim. Chang. Serv. Clim. Data Store (CDS), date access 26/05/2020 [online] Available from: https://cds.climate.copernicus.eu/cdsapp\#!/home, 2017.

Caesar, L., Rahmstorf, S., Robinson, A., G., F. and Saba, V.: Observed fingerprint of a weakening Atlantic Ocean overturning circulation, Nature, 556, 191-196, 2018.

Di Capua, G., Kretschmer, M., Donner, R. V., van den Hurk, B., Vellore, R., Krishnan, R. and Coumou, D.: Tropical and mid-latitude teleconnections interacting with the Indian summer monsoon rainfall: A Theory-Guided Causal Effect Network approach, Earth Syst. Dyn., 11, 17-34, doi:10.5194/esd-2019-11, 2020.

Chang, E. K. M., Ma, C., Zheng, C. and Yau, A. M. W.: Observed and projected decrease in Northern Hemisphere extratropical cyclone activity in summer and its impacts on maximum temperature, Geoph. Res. Lett., 43, 2200-2208, doi:10.1002/2016GL068172.Received, 2016. 
Christidis, N., Jones, G. S. and Stott, P. a.: Dramatically increasing chance of extremely hot summers since the 2003 European heatwave,

Cohen, J., Screen, J. A., Furtado, J. C., Barlow, M., Whittleston, D., Coumou, D., Francis, J., Dethloff, K., Entekhabi, D., Overland, J. and Jones, J.: Recent Arctic amplification and extreme mid-latitude weather, Nat. Geosci., 7, 627, 2014.

Cohen, J., Zhang, X., Francis, J., Jung, T., Kwok, R., Overland, J., Ballinger, T. J., Bhatt, U. S., Chen, H. W., Coumou, D., Feldstein, S., Gu, H., Handorf, D., Henderson, G., Ionita, M., Kretschmer, M., Laliberte, F., Lee, S., Linderholm, H. W., Maslowski, W., Peings, Y.,

325 Pfeiffer, K., Rigor, I., Semmler, T., Stroeve, J., Taylor, P. C., Vavrus, S., Vihma, T., Wang, S., Wendisch, M., Wu, Y. and Woon, J.: Divergent consensuses on Arctic amplification influence on midlatitude severe winter weather, Nat. Clim. Chang., 10(January), doi:10.1038/s41558-019-0662-y, 2020.

Connolly, R., Connolly, M., Soon, W., Legates, D. R., Cionco, R. G. and Herrera, V. M. V.: Northern hemisphere snow-cover trends (1967-2018): A comparison between climate models and observations, Geosci., 9(3), doi:10.3390/geosciences9030135, 2019.

330 Cortesi, N., Torralba, V., González-Reviriego, N., Soret, A. and Doblas-Reyes, F. J.: Characterization of European wind speed variability using weather regimes, Clim. Dyn., 53(7-8), 4961-4976, doi:10.1007/s00382-019-04839-5, 2019.

Coumou, D. and Rahmstorf, S.: A decade of weather extremes, Nat. Clim. Chang., 2(7), 1-6, 2012.

Coumou, D. and Robinson, A.: Historic and future increase in the global land area affected by monthly heat extremes, Environ. Res. Lett., 8, 0-6, 2013.

335 Coumou, D., Robinson, A. and Rahmstorf, S.: Global increase in record-breaking monthly-mean temperatures, Clim. Chang., 118(3-4), 771-782, 2013.

Coumou, D., Petoukhov, V., Rahmstorf, S., Petri, S. and Schellnhuber, H. J.: Quasi-resonant circulation regimes and hemispheric synchronization of extreme weather in boreal summer, Proc. Natl. Acad. Sci. U. S. A., 111(34), 12331-12336, 2014.

Coumou, D., Lehmann, J. and Beckmann, J.: The weakening summer circulation in the Northern Hemisphere mid-latitudes, Science, 340 348(6232), 324-327, 2015.

Coumou, D., Di Capua, G., Vavrus, S., Wang, L. and Wang, S.: The influence of Arctic amplification on mid-latitude summer circulation, Nat. Commun., 9(1), 2959, doi:10.1038/s41467-018-05256-8, 2018.

Ding, Q. and Wang, B.: Intraseasonal teleconnection between the summer Eurasian wave train and the Indian Monsoon, J. Clim., 20(15), 3751-3767, 2007.

345 Eyring, V., Bony, S., Meehl, G. A., Senior, C. A., Stevens, B., Stouffer, R. J. and Taylor, K. E.: Overview of the Coupled Model Intercomparison Project Phase 6 (CMIP6) experimental design and organization, Geosci. Model Dev., 9(5), 1937-1958, doi:10.5194/gmd9-1937-2016, 2016.

Faranda, D., Messori, G., Alvarez-Castro, M. C. and Yiou, P.: Dynamical properties and extremes of Northern Hemisphere climate fields over the past 60 years, Nonlin. Process. Geophys., 24(4), 713-725, doi:10.5194/npg-24-713-2017, $2017 \mathrm{a}$.

350 Faranda, D., Messori, G. and Yiou, P.: Dynamical proxies of North Atlantic predictability and extremes, Sci. Rep., 7, 41278, 2017b.

Faranda, D., Alvarez-Castro, M. C., Messori, G., Rodrigues, D. and Yiou, P.: The hammam effect or how a warm ocean enhances large scale atmospheric predictability, Nat. Commun., 10(1), 1316, doi:10.1038/s41467-019-09305-8, 2019.

Faranda, D., Messori, G. and Yiou, P.: Diagnosing concurrent drivers of weather extremes: application to warm and cold days in North America, Clim. Dyn., doi:10.1007/s00382-019-05106-3, 2020.

355 Fischer, E. M., Seneviratne, S. I., Vidale, P. L., Lüthi, D. and Schär, C.: Soil moisture-atmosphere interactions during the 2003 European summer heat wave, J. Clim., 20(20), 5081-5099, doi:10.1175/JCLI4288.1, 2007.

Freitas, A. C. M., Freitas, J. M. and Todd, M.: Hitting time statistics and extreme value theory, Probab. Theory Relat. Fields, 147(3), 675- 
https://doi.org/10.5194/wcd-2020-40

Preprint. Discussion started: 28 August 2020

(C) Author(s) 2020. CC BY 4.0 License.
Weather and

Climate Dynamics

Discussions

710, doi:10.1007/s00440-009-0221-y, 2010.

Gertler, C. G. and O'Gorman, P. A.: Changing available energy for extratropical cyclones and associated convection in Northern Hemisphere summer, Proc. Natl. Acad. Sci. U. S. A., 116(10), 4105-4110, doi:10.1073/pnas.1812312116, 2019.

Haarsma, R. J., Selten, F., Hurk, B. Vd, Hazeleger, W. and Wang, X.: Drier Mediterranean soils due to greenhouse warming bring easterly winds over summertime central Europe, Geophys. Res. Lett., 36(4), 1-7, doi:10.1029/2008GL036617, 2009.

Haarsma, R. J., Selten, F. M. and Drijfhout, S. S.: Decelerating Atlantic meridional overturning circulation main cause of future west European summer atmospheric circulation changes, Environ. Res. Lett., 10(9), 94007, doi:10.1088/1748-9326/10/9/094007, 2015.

365 Hall, T. M. and Kossin, J. P.: Hurricane stalling along the North American coast and implications for rainfall, npj Clim. Atmos. Sci., 2(1), 1-9, doi:10.1038/s41612-019-0074-8, 2019.

Hansen, J., Sato, M. and Ruedy, R.: Perception of climate change, Proc. Natl. Acad. Sci. U. S. A., 109(37), E2415-E2423, 2012.

Hochman, A., Alpert, P., Harpaz, T., Saaroni, H. and Messori, G.: A new dynamical systems perspective on atmospheric predictability: Eastern Mediterranean weather regimes as a case study, Sci. Adv., 5(6), eaau0936, doi:10.1126/sciadv.aau0936, 2019.

370 Horton, D. E., Johnson, N. C., Singh, D., Swain, D. L., Rajaratnam, B. and Diffenbaugh, N. S.: Contribution of changes in atmospheric circulation patterns to extreme temperature trends., Nature, 522(7557), 465-9, 2015.

Horton, R. M., Mankin, J. S., Lesk, C., Coffel, E. and Raymond, C.: A Review of Recent Advances in Research on Extreme Heat Events, Curr. Clim. Chang. Reports, 2016.

Hoskins, B. and Woollings, T.: Persistent Extratropical Regimes and Climate Extremes, Curr. Clim. Chang. Reports, 115-124, doi:10.1007/s40641-015-0020-8, 2015.

Huguenin, M. F., Fischer, E. M., Kotlarski, S., Scherrer, S. C., Schwierz, C. and Knutti, R.: Lack of Change in the Projected Frequency and Persistence of Atmospheric Circulation Types Over Central Europe, Geophys. Res. Lett., doi:10.1029/2019g1086132, 2020.

Lau, W. K.-M., Lee, J. Y., Kim, K. M. and Kang, I. S.: The North Pacific as a Regulator of Summertime Climate over Eurasia and North America, J. Clim., 17, 819-833, 2004.

380 Lehmann, J. and Coumou, D.: The influence of mid-latitude storm tracks on hot, cold, dry, and wet extremes, Sci. Rep., 5(17491), 1-9, 2015 .

Lehmann, J., Coumou, D., Frieler, K., Eliseev, A. V and Levermann, A.: Future changes in extratropical storm tracks and baroclinicity under climate change, Environ. Res. Lett., 9(8), 084002, 2014.

Lehmann, J., Coumou, D. and Frieler, K.: Increased record-breaking precipitation events under global warming, Clim. Change, 132(4), 501-515, 2015.

De Luca, P., Messori, G., Faranda, D., Ward, P. J. and Coumou, D.: Compound Hot-Dry and Cold-Wet Dynamical Extremes Over the Mediterranean, Earth Syst. Dyn. Discuss., 2020, 1-24, doi:10.5194/esd-2020-21, 2020a.

De Luca, P., Messori, G., Pons, F. M. E. and Faranda, D.: Dynamical Systems Theory Sheds New Light on Compound Climate Extremes in Europe and Eastern North America, Q. J. R. Meteorol. Soc., (146), 1636-1650, doi:10.1002/qj.3757, 2020 b.

390 Lucarini, V., Faranda, D. and Wouters, J.: Universal Behaviour of Extreme Value Statistics for Selected Observables of Dynamical Systems, J. Stat. Phys., 147(1), 63-73, doi:10.1007/s10955-012-0468-z, 2012.

Lucarini, V., Faranda, D., Freitas, J. M., Holland, M., Kuna, T., Nicol, M. and Vaienti, S.: Extremes and recurrence in dynamical systems, John Wiley \& Sons., 2016.

Mann, M. E., Rahmstorf, S., Kornhuber, K., Steinman, B. A., Miller, S. K. and Coumou, D.: Influence of Anthropogenic Climate Change on Planetary Wave Resonance and Extreme Weather Events, Sci. Rep., 7(March), 45242, 2017. 
https://doi.org/10.5194/wcd-2020-40

Preprint. Discussion started: 28 August 2020

(c) Author(s) 2020. CC BY 4.0 License.

Weather and

Climate Dynamics

(c) (1)

Manola, I., Selten, F., De Vries, H. and Hazeleger, W.: "Waveguidability” of idealized jets, J. Geophys. Res. Atmos., 118(18), 1043210440, doi:10.1002/jgrd.50758, 2013.

McKinnon, K. A., Rhines, A., Tingley, M. P. and Huybers, P.: Long-lead prediction of eastern United States hot days from Pacific sea surface temperatures, Nat. Geosci., (March), doi:10.1038/NGEO2687, 2016.

400 Messori, G., Caballero, R. and Faranda, D.: A dynamical systems approach to studying midlatitude weather extremes, Geophys. Res. Lett., 44(7), 3346-3354, doi:10.1002/2017GL072879, 2017.

Moloney, N. R., Faranda, D. and Sato, Y.: An overview of the extremal index, Chaos An Interdiscip. J. Nonlinear Sci., 29(2), 22101, doi:10.1063/1.5079656, 2019.

Nicholls, N. and Seneviratne, S.: Chapter 3 : Changes in Climate Extremes and their Impacts on the Natural Physical Environment, IPCC 405 SREX Rep., (July), 1-143, 2010.

O'Gorman, P. A.: Understanding the varied response of the extratropical storm tracks to climate change, Proc. Natl. Acad. Sci. USA, 107(45), 19176-19180, doi:10.1073/pnas.1011547107, 2010.

O’Neill, B. C., Tebaldi, C., van Vuuren, D. P., Eyring, V., Friedlingstein, P., Hurtt, G., Knutti, R., Kriegler, E., Lamarque, J.-F., Lowe, J., Meehl, G. A., Moss, R., Riahi, K. and Sanderson, B. M.: The Scenario Model Intercomparison Project (ScenarioMIP) for CMIP6, Geosci.

Model Dev., 9(9), 3461-3482, doi:10.5194/gmd-9-3461-2016, 2016.

Petrie, R. E., Shaffrey, L. C. and Sutton, R. T.: Atmospheric response in summer linked to recent Arctic sea ice loss, Q. J. R. Meteorol. Soc., 141(691), 2070-2076, 2015.

Pfahl, S., Schwierz, C., Croci-Maspoli, M., Grams, C. M. and Wernli, H.: Importance of latent heat release in ascending air streams for atmospheric blocking, Nat. Geosci., 8(8), 610-614, 2015.

415 Pfleiderer, P. and Coumou, D.: Quantification of temperature persistence over the Northern Hemisphere land-area, Clim. Dyn., 51(1-2), 627-637, doi:10.1007/s00382-017-3945-x, 2018.

Pfleiderer, P., Schleussner, C.-F., Kornhuber, K. and Coumou, D.: Summer weather becomes more persistent in a 2C world, Nat. Clim. Chang., doi:10.1038/s41558-019-0555-0, 2019.

Rahmstorf, S. and Coumou, D.: Increase of extreme events in a warming world, Proc. Natl. Acad. Sci. USA, 108(44), 17905-17909, 2011.

420 Routson, C. C., McKay, N. P., Kaufman, D. S., Erb, M. P., Goosse, H., Shuman, B. N., Rodysill, J. R. and Ault, T.: Mid-latitude net precipitation decreased with Arctic warming during the Holocene, Nature, 568(7750), 83-87, doi:10.1038/s41586-019-1060-3, 2019.

Schleussner, C.-F., Pfleiderer, P. and Fischer, E. M.: In the observational record half a degree matters, Nat. Clim. Chang., 7, $460,2017$.

Schneider, T., Bischoff, T. and Plotka, H.: Physics of changes in synoptic midlatitude temperature variability, J. Clim., 2014.

Shaw, T. A. and Voigt, A.: Tug of war on summertime circulation between radiative forcing and sea surface warming, Nat. Geosci., 8(7),

560-566, doi:10.1038/ngeo2449, 2015.

Shepherd, T. G.: Atmospheric circulation as a source of uncertainty in climate change projections, Nat. Geosci., 7, 703-708, 2014.

Sillmann, J. and Roeckner, E.: Indices for extreme events in projections of anthropogenic climate change, Clim. Chang., 86, 83-104, doi:10.1007/s10584-007-9308-6, 2008.

Sillmann, J., Kharin, V. V, Zhang, X., Zwiers, F. W. and Bronaugh, D.: Climate extreme indices in the CMIP5 multi-model ensemble. Part

1 : Model evaluation in the present, J. Clim., 118(in review), 1716-1733, $2013 \mathrm{a}$.

Sillmann, J., Kharin, V. V., Zwiers, F. W., Zhang, X. and Bronaugh, D.: Climate extremes indices in the CMIP5 multimodel ensemble: Part 2. Future climate projections, J. Geophys. Res. Atmos., 118(6), 2473-2493, 2013b. 
https://doi.org/10.5194/wcd-2020-40

Preprint. Discussion started: 28 August 2020

(c) Author(s) 2020. CC BY 4.0 License.
Weather and

Climate Dynamics

Discussions

Sillmann, J., Donat, M. G., Fyfe, J. C. and Zwiers, F. W.: Observed and simulated temperature extremes during the recent warming hiatus, Environ. Res. Lett., 9(064023), 1-8, doi:10.1088/1748-9326/9/6/064023, 2014.

435 Sussman, H. S., Raghavendra, A., Roundy, P. E. and Dai, A.: Trends in northern midlatitude atmospheric wave power from 1950 to 2099 , Clim. Dyn., 54(5-6), 2903-2918, doi:10.1007/s00382-020-05143-3, 2020.

Süveges, M.: Likelihood estimation of the extremal index, Extremes, 10(1), 41-55, doi:10.1007/s10687-007-0034-2, 2007.

Swain, D. L., Horton, D. E., Singh, D. and Diffenbaugh, N. S.: Trends in atmospheric patterns conducive to seasonal precipitation and temperature extremes in California, Sci. Adv., 2(4), 1-14, doi:10.1126/sciadv.1501344, 2016.

440 Teng, H. and Branstator, G.: Amplification of Waveguide Teleconnections in the Boreal Summer, Curr. Clim. Chang. Reports, 5(4), 421432, doi:10.1007/s40641-019-00150-x, 2019.

Trenberth, K. E. and Fasullo, J. T.: Climate extremes and climate change: The Russian heat wave and other climate extremes of 2010, J. Geophys. Res. Atmos., 117(D17), doi:10.1029/2012JD018020, 2012.

Wehrli, K., Hauser, M. and Seneviratne, S. I.: Storylines of the 2018 Northern Hemisphere heat wave at pre-industrial and higher global

445 warming levels, Earth Syst. Dyn. Discuss., 2020.

Westra, S., Alexander, L. V and Zwiers, F. W.: Global Increasing Trends in Annual Maximum Daily Precipitation, J. Clim., 26(11), 39043918, doi:10.1175/JCLI-D-12-00502.1, 2013. 